\title{
Assessment of the side effects of progestogen only contraception in the immediate postpartum period: the case of implants with levonorgestrel Jadelle®
}

\section{Moussa Diallo*, Abdoul Aziz Diouf, Astou Coly Niassy Diallo, Omar Gassama, Alassane Diouf}

Department of Medicine, Cheikh Anta DIOP of Dakar University, Senegal

Received: 11 March 2017

Accepted: 07 April 2017

\section{*Correspondence:}

Dr. Moussa Diallo,

E-mail: moussadiallo25@ hotmail.com

Copyright: () the author(s), publisher and licensee Medip Academy. This is an open-access article distributed under the terms of the Creative Commons Attribution Non-Commercial License, which permits unrestricted non-commercial use, distribution, and reproduction in any medium, provided the original work is properly cited.

\section{ABSTRACT}

Background: The aim of this study was to evaluate the side effects of Jadelle ${ }^{\circledR}$ implants in the immediate postpartum.

Methods: To do this, we inserted the implants at two different postpartum period: first, between the first and the seventh day for the immediate postpartum period (IPP) group; second, between the 45th and the 3rd postpartum months for the late postpartum (LPP) group. The variables studied were age, gesture, parity, abortions, number of live children, childbirth, caesarean section, quality of milky climb, age last child, pregnancy-attendant, pregnancy term at time of delivery, complaints, weight.

Results: From May 2012 to December 2013, we collected two hundred patients, one hundred from each group (immediate postpartum and late postpartum). The average age of mothers in the IPP group was 28 years and 29 years for LPP group. After insertion, in both group, spotting were the most frequent complaints. The weight variations were between $+800 \mathrm{~g}$ and $-600 \mathrm{~g}$ for the group IPP and $+260 \mathrm{~g}$ and $-170 \mathrm{~g}$ for the other group; which makes a statistically significant difference. In both groups, at the end of the six months, no patient had menstruation.

Conclusions: Our results are encouraging to further promote contraception in the immediate postpartum period in developing countries and thus reach a wide range of users. We can therefore say that the side effects are not different during this period and largely are also tolerated.

Keywords: Contraception progestogen, Immediate postpartum, Implants, Progestogen

\section{INTRODUCTION}

In sub-Saharan Africa, maternal mortality remains at a worrying level. Every year more than 500,000 women lose their lives by giving birth. In Senegal, it is currently 392 per 100,000 live births. ${ }^{1}$ Birth spacing has been strongly advised by world health organization (WHO) to reduce these alarming rates. Immediate postpartum can be widely depicted by high-profile hospitals such as ours to reduce missed opportunities. Indeed, most of the patients are referred to other structures. The use of progestin implants offers a double advantage. It is a method without estrogen and is a long-term contraception. Most of the studies performed on implants were done during gynecological periods and unknown side effects in recent mothers. This study was conducted to investigate the safety of progestin-only contraceptive implants in the immediate postpartum by analyzing the side effects of levonorgestrel during this period.

\section{METHODS}

We included in this study all patients who had a natural birth or caesarean delivery in our service during the 
collection period, who accepted the contraceptive method by Jadelle $\AA$ implants after counseling and who were not contraindicated for this method. We don't include all patients with contraindications for the use of hormonal contraception or breast-feeding and newborns with a severe condition and finally patients who did not consent to the use of the method.

The insertion was made after delivery before returning home or during post-natal consultations. It occurred between the first and the seventh day of the postpartum period for the immediate postpartum period (IPP) group and between the 45 th and the $3^{\text {rd }}$ postpartum months for the late postpartum (LPP) group at the internal side of the arm (of the non-dominant member). The procedue was practiced by the same practitioner. From the date of insertion, patients were monitored on a monthly basis. During the post-insertion consultations, patients were completely clinical examinated.

All the patients were examined by the same practitioner. The variables studied were age, marital status, educational attainment, gesture, parity, abortions, number of live children, childbirth, caesarean section, quality of milky climb, age last child, contraception, pregnancyattendant, pregnancy term at time of delivery, complaints, weight. The data collected was processed using the EXCEL software for Windows Office 2007 for the global computerization of data and the production of tables and figures and SPSS 17.0 for Windows for the calculation of means and tests of significance.

\section{RESULTS}

From May 2013 to December 2014, we collected two hundred patients, one hundred from each group (immediate postpartum and late postpartum). The results obtained were as follows.

\section{Age and parity}

The average age of mothers in the IPP group was 28 years with extremes of 16 years and 42 years. That of the mothers of the LPP group was 29 years with extremes of 15 years and 43 years. The two groups appear to be identical when considering the age of the patients $(p=$ 2.5). The parity of the patients was globally superposable in both groups $(\mathrm{p}=0.99)$.

\section{Intergenic interval}

For patients with parity greater than or equal to 2 , the average interval between the two last pregnancies for the IPP group was on average 20 months, with a maximum of 84 months. For the LPP group the mean interval was 17 months with a maximum of 144 months. In both groups, the proportion of women who had never contracted was higher; $70 \%$ for the late postpartum group and $74 \%$ for the immediate postpartum group.

\section{Delivery route}

In both groups, caesarean section was the most common delivery route, $86 \%$ for the late postpartum group and $70 \%$ for the immediate postpartum group. There was no significant difference between the two groups $(p=0.53)$.

\section{Period of insertion of the implants}

In the IPP group, insertions were made on the third postpartum day for the majority of patients (86\%), and they were all done before the seventh day. The LPP group took place at six weeks $(78 \%)$ and rarely more than two months (four cases only).

\section{Milky ascent}

When the implants were inserted, the milky climb was considered satisfactory, as well as during post-natal consultations for all patients. For the four patients who received the implants before the $3^{\text {rd }}$ day of postpartum, the date of the milky climb was the same as for the other patients.

\section{Complaints}

In both group, spotting and leucorrhea were the most frequent complaints. However, in the IPP group, the patients with spotting were significantly more numerous than the other group (Table 1).

Table 1: Distribution of major complaints in both group.

\begin{tabular}{|lll|}
\hline & Groups & \\
\hline Complaints & LPP & IPP \\
\hline Spotting & 17 & 30 \\
\hline Leucorrhea & 8 & 6 \\
\hline Headache & 1 & 4 \\
\hline
\end{tabular}

\section{The period of the return of layers and amenorrhea}

Indeed, overall, only $22 \%$ of the patients had their menstruation during the six months of follow-up in the IPP group. This "primitive" amenorrhea of progressive installation was more pronounced in the LPP group. And in both group, at the end of the six months, no patient had menstruation. After insertion of the implants, we found that the proportion of patients with amenorrhea increased over time.

\section{Weight changes}

The mean weight of the patients was unchanged in both groups. There was no evidence of continuous weight gain in either group. The weight variations were between+ $800 \mathrm{~g}$ and-600g for the group IPP and $+260 \mathrm{~g}$ and $-170 \mathrm{~g}$ for the other group; which makes a statistically significant difference (Figure 1). But it is difficult to interpret this difference due to the involvement of other factors 
(environment, diet). The weight at the first prenatal visit was taken as a reference.

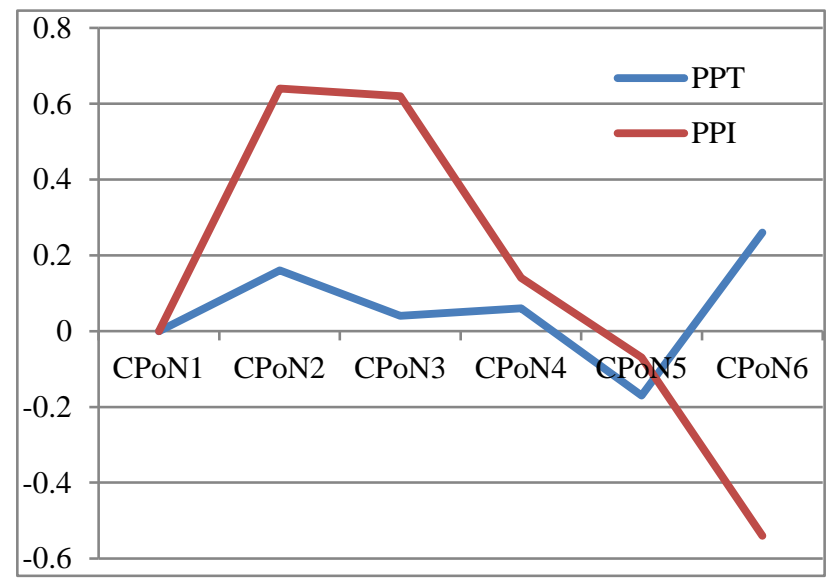

Figure 1: Evolution of the mean weight of the patients in the two groups.

\section{DISCUSSION}

In sub-Saharan Africa, maternal mortality remains at a worrying level. Every year more than 500,000 women lose their lives by giving birth. In Senegal, it is currently 392 per 100,000 live births. ${ }^{1}$ The neonatal and infant morbidity and mortality were then deeply affected. Contraception may help lower some complications related to tachyparity.

It has long been recommended by the World Health Organization (WHO) as an ideal intergeneric space to preserve the health of mothers and newborns and infants. This interval was at least 24 months. ${ }^{2}$ At the same time, the contraceptive coverage of the population was very insufficient, due to the under-medicalization and the young age of the women and therefore a certain psychologic immaturity. The postpartum period seems to us to be a good time to establish this contraception for the long term. Progestational contraception was the most studied because of the absence of estrogen. ${ }^{3}$ The longterm objective was to avoid the deleterious effects of estrogens in the immediate postpartum period (thromboembolic events and its passage through breast milk) in order to obtain better contraceptive coverage with a lower dropout rate. Previous studies have all focused on the use of implants after six weeks. Their introduction of the first days of postpartum is a first but also improve the contraceptive prevalence and provision of care within a maternity level 3 who receives many potentially lethal complications.

In these situations, preventing the occurrence of a new pregnancy before the next two years is paramount. Several side effects, expected and perfectly manageable, undermine the observance of this method. We were interested in the three main complaints reported by the users of this method. These include irregular bleeding, headache and weight changes.

\section{Irregular bleeding and amenorrhea}

The most feared side effect of progestin-only contraception is probably spotting. They are in fact less well tolerated than progestin-induced secondary amenorrhea. They are due to induced estrogen deficiency. In an attempt to reduce these adverse effects and thus the drop-out rate, Jadelle ${ }^{\circledR}$ implants were a good alternative. However, there was little experience of its use in the immediate postpartum. ${ }^{4}$ The results are similar to those of patients using the UTc 380 copper intrauterine device in terms of cyclic disorders (secondary amenorrhea) during their conventional use (at six weeks). ${ }^{5}$ In our study, $60 \%$ of patients in the IPP group and $34 \%$ in the LPP group had irregular bleeding.

All our patients were amenorrhoea after six months of follow-up. These high rates of bleeding appear to be an abnormal prolongation of the lochia. Management was based on the administration of ibuprofen and no patients had abandoned the method at the end of the six months of the study. These bleeds are becoming better known and well taken care of. However, in order to increase their adhesion, good information of the patients is essential.

\section{Headache}

Their frequency ranged from 3 to $69 \%$ (43\% in the United States, and $69 \%$ in Chile) for Norplant ${ }^{\circledR}$ implants, $45 \%$ in a study with Implanon ${ }^{\circledR}$ performed immediately after childbirth in patients without prior cardiovascular disease. ${ }^{6-8}$ These data are consistent with our findings for LPP patients but not for IPP patients. Their exact origin is not known. In our study, headache was transient and difficult to relate to contraceptive use.

\section{Weight changes}

This is mainly about weight gain. It is the second complaint after menstrual cycle disorders. Weight gain under hormonal contraception is not predictable and is a real barrier for health providers. The phenomenon appears a priori more-frank with the methods combined with estrogens and even the medroxyprogesterone acetate (Depo-Provera®), but that does not constitute an advantage for the implants. A study in China comparing patients with Norplant ${ }^{\circledR}$ and copper-bearing IUD showed an average gain of $2.5 \mathrm{~kg}$ after 5 years of use of Norplant ${ }^{\circledR}$. However, this weight gain was only $1 \mathrm{~kg}$ compared to the group of patients under IUD. ${ }^{9,10}$ This study proves that the share of hormonal contraception in weight gain is not so different from other non-hormonal methods. But caution must be exercised in interpreting these data. Other studies carried out to evaluate weight gain only under progestogen contraception (only implants) in the postpartum and in the gynecological period over a 3-year period concluded that an average weight gain of 0.4 And $1.5 \mathrm{~kg}$ per year for all methods (Norplant $\AA$, Jadelle $\AA$, Uniplant ${ }^{\circledR}$ and Implanon $\AA$ ). The mean overall weight gain was $350 \mathrm{~g}$ and $790 \mathrm{~g}$ 
respectively for the LPP group and the IPP group in our study. ${ }^{11-13}$

\section{CONCLUSION}

These results are encouraging to further promote contraception in the immediate postpartum period in developing countries and thus reach a wide range of users. Thus, to avoid missed opportunities, a contraception can be immediately proposed by the medical team taking advantage of this crucial period. But no doubt, a more prolonged surveillance is essential to reinforce these results. We can therefore say that the side effects are not different during this period and largely are also tolerated.

Funding: No funding sources

Conflict of interest: None declared

Ethical approval: The study was approved by the Institutional Ethics Committee

\section{REFERENCES}

1. ANSD. Agence Nationale de la Statistique et de la Démographie. Enquête Démographique et de Santé Sénégal 2014. EDS continue; 2014.

2. USAID. Accélérer l'accès à la planification familiale du postpartum (PFPP) en Afrique sub-saharienne et en Asie: Fiche de travail des stratégies de programmation pour la PFPP; 2013.

3. Wilson S, Tennant C, Sammel MD, Schreiber C. Immediate postpartum etonogestrel implant: a contraception option with long-term continuation. Contraception. 2014;90:259-64.

4. Hubacher D, Lopez L, Steiner MJ, Dorflinger L. Menstrual pattern changes from levonorgestrel subdermal implants and DMPA: systematic review and evidence-based comparisons. Contraception. 2009;80:113-8.

5. Meirik O, Brache V, Orawan K, Habib NA, Schmidta J, Ortayli N, et al. A multicenter randomized clinical trial of one-rod etonogestrel and two-rod levonorgestrel contraceptive implants with nonrandomized copper-IUD controls: methodology and insertion data. Contraception. 2013;87:113-20.

6. Ba M, Moreau JC, Sokal D. A 5-year clinical evaluation of Norplant implants in Senegal. Contraception. 1999;59:377-81.

7. Shaaban M, Salem H, Abdullah K. Influence of levonorgestrel contraceptive implants, Norplant, initiated early postpartum upon lactation and infant growth. Contraception. 1985;32:623-35.

8. Harrisa M, Kaneshirob B. An evidence-based approach to hormonal contraception and headaches. Contraception. 2009;80:417-21.

9. Norplant ICP-MSo. Post-marketing surveillance of Norplant contraceptive implants: II. Nonreproductive health; 2001:187-209.

10. Bellagio. Consensus Conference on Lactational Infertility. Bellagio Consensus statement on the use of breastfeeding as a family planning method. Contraception. 1989;39(5):477-96.

11. Coutinho E. One year contraception with a single subdermal implant containing nomegestrol acetate (Uniplant). Contraception. 1993;47:97-105.

12. Zenger E, Qiu S, Fang H. Introduction of Norplant implants in four countries of rural China: a two-year evaluation. Contraception. 1995;52:349-55.

13. Coutinho EJd, Athayde C. Multicenter clinical trial on the efficacy and acceptability of a single contraceptive implant of nomegestrol acetate, Uniplant. Contraception. 1996;53:121-5.

Cite this article as: Diallo M, Diouf AA, Diallo ACN, Gassama O, Diouf A. Assessment of the side effects of progestogen only contraception in the immediate postpartum period: the case of implants with levonorgestrel Jadelle®. Int J Reprod Contracept Obstet Gynecol 2017;6:1733-6. 